\title{
Comparative Study on Physiological and Motor Fitness Variables among Different Types of Special Students
}

\author{
Dr. Gopa Saha Roy ${ }^{1 *}$, Mr. Priyatosh Mondal ${ }^{2}$, Miss. Neetu Dutta ${ }^{3}$
}

${ }^{1}$ Associate Professor Department Phy.Edu, The University of Burdwan, Burdwan Rajbati, Raiganj, Bardhaman, West Bengal 713104, India
${ }^{2}$ Master of Physical Education, The University of Burdwan, Burdwan Rajbati, Raiganj, Bardhaman, West Bengal 713104, India
${ }^{3}$ Assistant Teacher, Jagatdal Lalita Devi Balika Vidyalaya, North 24 Pargana, West Bengal, India

DOI: $10.36348 /$ jaspe.2020.v03i04.001

| Received: 19.12.2019 | Accepted: 03.02.2020 | Published: 30.04 .2020

*Corresponding author: Dr. Gopa Saha Roy

\section{Abstract}

Physically challenge is the consequence of an impairment that may be physically, cognitive, mental, emotional, development or some combination of these. Objective: The purpose of the present study was to examine the health status, peak expiratory flow (PEF) and flexibility, motor fitness component of physically challenge school boy and compare them. Method: A total of ten $(\mathrm{N}=10)$ physically challenged boys was chosen randomly for this study, among them ten $(\mathrm{N}=10)$ were orthopedically disabled $(\mathrm{OC})$, ten $(\mathrm{N}=10)$ were hearing impaired $(\mathrm{HI})$ and ten $(\mathrm{N}=10)$ were visual impaired (VI). BMI, PEF, flexibility, motor fitness component were the criterion measure of this study. Mean SD were calculated as descriptive statistics and significance of inter group difference was analysis by ANOVA only 0.05 level was consider to judge the significance of the study. All the statistical procedure was done by the standard statistical software. Result: Result revealed that significant difference exist $(\mathrm{P}>0.05)$ in respect of BMI $(\mathrm{F}=6.5)$ among this $\mathrm{OH}, \mathrm{VI}$, HI. Mean value of challenged pupil was between WHO, IMCMR standard. Result also showed that significant difference exist $(0.05$ level) in respect of physiological and motor fitness variables among OC, VI and subjects. All group of the physically challenge boys of 14-16years old had lower health standard in respect of national and international standard in respect. Conclusion: The physical challenged boys of $14-16$ year old had lower health standard in respect of national and international standard and they are significant difference in physically variables (PEF) and motor fitness variable (Flexibility) and physiological variables among the groups viz. HI,OC AND VI. From the result we revealed that in respect of BMI, physiological and motor fitness variables point of view, I group was more healthy than HI \& OC group In respect.

Keywords: VI- Visual Impaired, OC- Orthopedically Challenged, HI- Hearing Impaired, PEF-Pick Exploratory Flow Rate, BMI- Body Mass Index, BPSYS- Systolic Blood Pressure, BPDIA- Diastolic Blood Pressure, RHR- Resting Heart RATE.

Copyright @ 2020: This is an open-access article distributed under the terms of the Creative Commons Attribution license which permits unrestricted use, distribution, and reproduction in any medium for non-commercial use (NonCommercial, or CC-BY-NC) provided the original author and source are credited.

\section{INTRODUCTION}

Physical fitness is to the human body what fine tuning is to an engine. It enables us to Perform up to our potential. Fitness can be described as a condition that helps us look, Feel and do our best [1]. Physical fitness involves the performance of the heart and lungs, and the muscles of the Body. And, since what we do with our bodies also affects what we can do with our Minds, fitness influences to some degree qualities such as mental alertness and Emotional $\mathrm{s}$ stability (M.T MEDICAL) [2]. Fitness is an essential part of life. The important of fitness in our health has been stressed by various experts. Regular exercises are a critical part of staying healthy and fit. People who are performing physical activity their life become longer and feel better. In this context, the researcher takes the responsibilities to pick the selected anthropometric measurements, physiological and motor fitness variable among different category physically challenged students [3]. Not long ago individual having some physical or mental defects were located down upon as useless persons for the society. The term Handicapped or disabled were levelled against their identity. They were not whole heartedly accepted by other in the society - with the passage of time the outlook began to change. Social reformers and educationalists are striving hard to integrate the Physically Challenged Persons with the main stream. For the inhuman treatment method to thaw earlier the most dreaded effect was lack of confidence, depression and self reliance [4]. First in China gymnastic was being used as a part of sports therapy for those individual. Later on 
other sporting event were introduced with slight modification as a part of the educational programme for the challenged person or differently able person. Thus the birth of a new educational system, adapted physical education came into existence. The international games for these special people are being held in various parts of the world at regular interval. Success in such meets gives confidence to those people who thereon have the feeling that they can also be worth of something. Among various special populations deaf and dumb is a very common type of disability seen in our society not in a very negligible quantity. It is needed to take special care and attention of this population from their children to give them ample opportunity to be self sufficient to future [5]. That is why various schools have been established for the special populations in our country starting from late seventies up to date. It is needed not only to give them education but also to build a healthy body and mind for them having the prime necessity of Physical Education as well to make them conscious about their physique, health and fitness [6].

A sincere attempt is made to know the research work already done in the subject area the gaps and weakness of the past research, the methods logy used and procedure followed from professional literature. Considering the research work in the field it can be concluded that a very little effort has been taken so far on the special population like deaf and dumb in India. Accordingly the present project is planned to initiate research work related to the physical and physiological functioning of normal school children and deaf and dumb children if comparative stand point [7].

\section{STATEMENT OF THE PROBLEM}

The researcher has stated this study as "A Comparative Study on Physiological and Motor Fitness Variables among different types of Special Student"

\section{PURPOSE OF THE STUDY}

1. It provide from information among the physiological and motor fitness level of Hearing impaired student.

2. It provide from information among the physiological and motor fitness level of Visual impaired student.

3. 3. It provide from information among the physiological and motor fitness level of Orthopedically Challenged student.

\section{HYPOTHESIS}

HI: There will be significant differences in health status between the different categories of challenged students.

H0: There will be no significant differences in motor fitness and physiological fitness between the different categories of challenged Students.

\section{SIGNIFICAI CE OF THE STUDY}

1. The result would provide knowledge about physiological and motor fitness different category of challenged students.

2. The result would help to understand whether there are any significant differences in physiological and motor fitness of different category of challenged students.

3. The result of study would enrich of physical education.

4. The result of the study would enrich of physical education, coach, about the physiological and motor fitness quality of different challenged student.

5. The study would help in future to know and to work on different challenged student.

\section{METHODOLOGY THE SUBJECT}

Total of thirty subjects $(\mathrm{N}=30)$ were randomly chosen for this project of which 10 were hearing impaired. 10 were visual impaired and rest 10 were orthopedically handicapped. All subjects were selected from Dr. Sailendranath Mukherjee Mukh A Badhir Vidyalaya, a school for special population at Burdwan district and their age ranged between $14-16$ years

\section{DESIGN OF THE STUDY}

Multiple group design with three independent means was considered for this study. The physiological and motor fitness components were compared between three physically challenged students groups i.e. hearing impaired, visual impaired, orthopedically challenged. Personal Data - Age, Height, Weight, BMI.

\section{CRITERIA MEASURES}

The criterions were considered i.e. (a) physiological variables, Peak expiratory flow (PEF), BP Sys, BP Dia, RHR and (b) motor fitness variables flexibility, speed, ability, and explosive strength.

\section{STATISTICAL PROCEDURE}

For the analysis of collected data formulating statistical treatment were used. Mean, SD was used for descriptive statistic and for the among mean different ANOVA was used. The level of significant was set at 0.05 level of confidence.

\section{ANALYSIS OF DATA}

Statistical analysis of data to find out the result of the study, analysis and interpretation of the results in the light of the existing knowledge of field and testing of hypotheses formulated in the beginning of this Project have been presented is this chapter.

\section{Personal Data}

The data regarding height, weight and BMI of the three Special Population Students (SPS) category have been presented in Table-1. 
Table-1

\begin{tabular}{|l|l|l|l|l|l|l|}
\hline Category of SPS & \multicolumn{2}{|l|}{ Height $(\mathbf{C m})$} & \multicolumn{2}{l|}{ Weight $\mathbf{( K g )}$} & \multicolumn{2}{l|}{ BMI $\left(\mathbf{K g} / \mathbf{m}^{2}\right)$} \\
\hline & M & SD & M & SD & M & SD \\
\hline Hearing Impaired (HI) & 161.1 & 6.56 & 41.7 & 6.18 & 16.07 & 2.31 \\
\hline Visual Impaired (VI) & 150.8 & 12.48 & 47.1 & 9.3 & 20.86 & 3.94 \\
\hline Orthopaedic Challenged (OC) & 150.7 & 13.51 & 40.3 & 6.49 & 17.8 & 2.24 \\
\hline
\end{tabular}

Table-1 indicated that mean and standard deviation of height of HI, VI and $\mathrm{OH}$ were 161.1, 6.56: $150.8,12.48$ and $150.7,13.51$ respectively. The mean and standard deviation of weight of HI, VI and OC were $41.7,6.18 ; 47.1,9.3$ and 40.3, 6.49 respectively. The mean and standard deviation of BMI of HI, VI and OC were $16.07,2.31 ; 20.86,3.94$ and $17.8,2.24$ respectively.

As the mean value of height, weight and BMI for $\mathrm{HI}, \mathrm{VI}$ and OC were different, therefore ANOVA was computed to find out inter group difference between means and result presented in Table-2.

Table-2: Analysis of Variance (ANOVA) for Height, Weight and BMI of SPS

\begin{tabular}{|l|l|l|l|l|l|}
\hline Parameters & Sources of Variance & $\boldsymbol{d} \boldsymbol{f}$ & Sums of Squares & Mean Square Variance & F \\
\hline \multirow{3}{*}{ Height } & Among the means of Groups & 2 & 714.2 & 357.1 & 2.895 NS \\
\cline { 2 - 6 } & Within the Groups & 27 & 3330.2 & 123.34 & \\
\hline \multirow{2}{*}{ BMI } & Among the means of Groups & 2 & 257.87 & 128.94 & 2.314 NS \\
\cline { 2 - 5 } & Within the Groups & 27 & 1504.31 & 55.71 & \multirow{2}{*}{$5.298 *$} \\
\cline { 2 - 5 } & Among the means of Groups & 2 & 117.72 & 58.86 & \\
\hline
\end{tabular}

NS = Not significant at 0.05 level (To be significant the F-value should be 3.35). * Significant at 0.05 level.

Table-2 Indicated that F-value for height and weight for SPS were 2.895 and 2.314 and these Fvalues were not significant statistically. The F-value for BMI of SPS was 5.298 and this value found statistically significant.
As the F-value found significant therefore significance lies between two groups was analyzed by ttest. Result presented in Table-3.

Table-3: Results of t-test for BMI at Immediate after Exercise condition for different groups

\begin{tabular}{|l|l|l|l|}
\hline Groups Considered & Mean Difference & SED & 't' \\
\hline HI and VI & 10.3 & 1.53 & $3.13^{*}$ \\
\hline VI and OC & 0.10 & 1.53 & $2.00 \mathrm{NS}$ \\
\hline OC and HI & 10.4 & 1.53 & $1.13 \mathrm{NS}$ \\
\hline
\end{tabular}

* Significant at 0.05 level (To be significant the t-value should be 2.05) NS = Not significant.

Table-3 Indicated that inter group difference between VI and HI SPS $(\mathrm{t}=3.13)$ was statistically significant. But inter group difference between VI and OC and OC and HI SPS ( $\mathrm{t}=2.00$ and 1.13) were not significant statistically.

\section{Physiological Variables}

As the mean value of PEF, BP Sys, BP Dia, RHR for HI, VI and OC were different, therefore Mean and SD were computed to find out means and result presented in Table-4.

Table-4: The mean and standard deviation values of physiological variables of HI, VI and OC SPS

\begin{tabular}{|l|l|l|l|l|l|l|}
\hline Parameter & HI & VI & OC \\
\hline & Mean & SD & Mean & SD & Mean & SD \\
\hline PEF & 262.50 & \pm 110.23 & 296.50 & \pm 150.55 & 87.00 & \pm 56.78 \\
\hline BPSys & 121.40 & \pm 14.38 & 121.40 & \pm 9.80 & 121.20 & \pm 14.92 \\
\hline BPDia & 71.00 & \pm 11.45 & 69.90 & \pm 7.07 & 69.70 & \pm 9.22 \\
\hline RHR & 83.70 & \pm 9.97 & 76.60 & \pm 18.23 & 85.70 & \pm 15.28 \\
\hline
\end{tabular}

The mean and SD of PEF, BPSys, BPDia and RHR of HI, VI and OC have presented in Table-4. Table- 4 indicated that the mean and SD of PEF of HI, VI and OC were $262.50 \pm 111.23 ; 296.50 \pm 150.55$; and $87.00 \pm 56.78$ respectively. The mean and SD of BPSys of HI, VI and OC were $121.40 \pm 14.38 ; 121.40 \pm 9.80$; $121.20 \pm 9.80 ; 121.20 \pm 14.92$ respectively. The mean and SD of BPDia of HI, VI and OC were $71.00 \pm 11.45$;
$69.90 \pm 7.07 ; 69.70 \pm 9.22$ respectively. The mean and SD of RHR of HI, VI and OC were 83.70 $\pm 9.97 ; 76.60$ \pm 13.23 and $85.70 \pm 15.28$ respectively.

To find out inter group difference ANOVA was computed and result have presented in Table-5. Table -5 have shown that F-value for FER and BPDia were also significant statistically. 
Table-5: 'F' Values of physiological variables of HI, VI and OC SPS groups

\begin{tabular}{|l|l|l|l|l|l|}
\hline Parameters & Sources of Variance & $\boldsymbol{D} \boldsymbol{f}$ & Sums of Squares & Mean Square Variance & F \\
\hline \multirow{3}{*}{ PEF } & Among the means of Groups & 2 & 252821.66 & 126410.83 & \multirow{2}{*}{$9.998 *$} \\
\cline { 2 - 5 } & Within the Groups & 27 & 341375.0 & 12643.519 & \multirow{2}{*}{$0.001 \mathrm{NS}$} \\
\hline \multirow{2}{*}{ BPSDia } & Among the means of Groups & 2 & 0.267 & 0.133 & \\
\cline { 2 - 5 } & Within the Groups & 27 & 4732.40 & 175.275 & \multirow{2}{*}{$0.055 *$} \\
\cline { 2 - 5 } & Among the means of Groups & 2 & 9.80 & 4.900 & \multirow{2}{*}{$1.036 \mathrm{NS}$} \\
\cline { 2 - 5 } & Within the Groups & 27 & 2397.00 & 88.778 & \\
\hline
\end{tabular}

*Significant at 0.05 level of confidence (df $27=3.35$ ) NS = Not significant.

Table-6: Result of 'p' values of PEF and BPDia immediate after exercise conditions for different groups

\begin{tabular}{|l|l|l|c|}
\hline PEF SPSG & Mean Difference & SED & 'p' \\
\hline HI and VI & 34.00 & 50.286 & $0.505 \mathrm{NS}$ \\
\hline VI and OC & 209.50 & 50.286 & $0.000 *$ \\
\hline OC and HI & 175.50 & 50.286 & $0.002 *$ \\
\hline BPDia SPSG & Mean Difference & SED & 'p' \\
\hline HI and VI & 1.10 & 4.21 & $0.796 \mathrm{NS}$ \\
\hline VI and OC & 0.20 & 4.21 & $0.962 \mathrm{NS}$ \\
\hline OC and HI & 1.30 & 4.21 & $0.760 \mathrm{NS}$ \\
\hline
\end{tabular}

*Significant at 0.05 level (To be significant the t-value should be 2.05) NS = Not significant.

Table-6, indicated that inter group difference between HI Vs VI SPSG ( $\mathrm{p}=0.505)$ was not significant. But inter group difference between VI and OC and OC and HI SPSG ( $p=0.000$ and 0.002) were highly significant statistically.

\section{Motor Fitness Variables}

Table-7: Mean and SD of Motor Variables of HI, VI and OC of SPSG

\begin{tabular}{|l|l|l|l|l|l|l|}
\hline \multirow{2}{*}{ Variables } & \multicolumn{2}{l}{ HI } & \multicolumn{2}{l|}{ VI } & OC \\
\cline { 2 - 7 } & Mean & SD & Mean & SD & Mean & SD \\
\hline Speed & 7.56 & 0.823 & 6.83 & 0.424 & 12.46 & 2.027 \\
\hline Agility & 11.12 & \pm 1.026 & 10.36 & \pm 0.406 & 17.07 & 2.50 \\
\hline Flexibility & 13.00 & \pm 2.666 & 14.50 & \pm 0.707 & 10.40 & 1.77 \\
\hline Explosive Strength & 2.21 & \pm 0.077 & 2.47 & \pm 0.107 & 1.46 & 0.386 \\
\hline
\end{tabular}

It was found from the Table-7 that the mean and SD of speed of SPS group is $7.56 \pm 0.823 ; 6.83 \pm$ $0.424 ; 12.46 \pm 2.02$.

In was also found from table no. 7 that the mean and SD of flexibility of HI was $13.00 \pm 2.666$; VI was $14.50 \pm 0.707$; OC was $10.40 \pm 1.77$ respectively. Orthopedically challenged SPS group was in good condition (more flexible) than their counterpart.

From Table-7 it was found that the mean and SD of explosive leg strength of HI group was $2.21 \pm$ 0.077 ; VI group was $2.47 \pm 0.107$; OC was $1.46 \pm 0.386$ respectively. VI group was better strength than their counter parts.

Table-8: Analysis of Variance (ANOVA) for motor fitness variables of SPSG

\begin{tabular}{|c|c|c|c|c|c|}
\hline Parameters & Sources of Variance & $d f$ & Sums of Squares & Mean Square Variance & $\mathbf{F}$ \\
\hline \multirow[t]{2}{*}{ Speed } & Among the means of Groups & 2 & 186.960 & 93.480 & \multirow[t]{2}{*}{$56.736 *$} \\
\hline & Within the Groups & 27 & 44.725 & 1.658 & \\
\hline \multirow[t]{2}{*}{ Agility } & Among the means of Groups & 2 & 270.014 & 135.007 & \multirow[t]{2}{*}{$53.938 *$} \\
\hline & Within the Groups & 27 & 67.581 & 2.503 & \\
\hline \multirow[t]{2}{*}{ Flexibility } & Among the means of Groups & 2 & 86.067 & 43.033 & \multirow[t]{2}{*}{11.99} \\
\hline & Within the Groups & 27 & 96.900 & 3.589 & \\
\hline \multirow[t]{2}{*}{ Explosive Strength } & Among the means of Groups & 2 & 5.581 & 2.790 & \multirow[t]{2}{*}{$50.23 *$} \\
\hline & Within the Groups & 27 & 1.500 & 0.056 & \\
\hline
\end{tabular}

*Significant at 0.05 level of confidence. (df $27=3.35$ ) NS = Not significant. 
It was found from Table- 8 that HI SPS group of boys between the group value are sum of square 186.960, means square variable 93.480 and within the group are 44.723 , means square variance 1.658 and' $F$ ' value is 56.738 and it significant at 0.05 level of confidence $\operatorname{df}(27)=3.35$. it was observed that there had significant difference in speed among three groups.
In Table-8 among the three groups in flexibility ' $F$ ' value significant at 0.05 level of confidence.

From Table-8 'F' value of explosive leg strength among three group values are significant at 0.05 level of confidence (df $27=3.35$ ) calculated was 50.23 .

Table-9: Result of ' $t$ ' test for speed at immediate after exercise condition for different groups

\begin{tabular}{|l|l|l|c|}
\hline SPSG & Mean Difference & SED & ' $t$ ' value \\
\hline HI and VI & 0.728 & 0.575 & $0.217 \mathrm{NS}$ \\
\hline VI and OC & 5.622 & 0.575 & $0.000 *$ \\
\hline OC and HI & 4.894 & 0.575 & $0.000 *$ \\
\hline
\end{tabular}

*Significant at 0.05 level of confidence. (df $18=0.05$ ) NS = Not significant.

Table-9 stated that HI VS VI groups value is not significant at 0.05 level but other two groups difference are significant at 0.05 level of confidence, which was (0.000 and 0.000) and also stated that above mentioned groups were not in better speed than OC Vs VI group and OC Vs HI groups.
From Table-9 ' $t$ ' value of explosive leg strength HI Vs VI group was not significant but other two groups values were significant at 0.05 level of confidence $(0.000$ and 0.000$)$ respectively at df $28=$ 2.05 .

Table-10: Result of ' $t$ ' test for agility at immediate after exercise condition for different groups

\begin{tabular}{|l|l|l|c|}
\hline SPSG & Mean Difference & SED & ' $\mathbf{t}$ ' value \\
\hline HI and VI & -0.728 & 0.575 & $0.217 \mathrm{NS}$ \\
\hline VI and OC & -5.622 & 0.575 & $0.000^{*}$ \\
\hline OC and HI & -4.894 & 0.575 & $0.000 *$ \\
\hline
\end{tabular}

*Significant at 0.05 level of confidence. (df $18=0.05) \mathrm{NS}=$ Not significant.

Table-11: Result of ' $t$ ' test for explosive strength at immediate after exercise condition for different groups

\begin{tabular}{|l|l|l|r|}
\hline SPSG & Mean Difference & SED & 't' value \\
\hline HI and VI & 0.268 & 0.105 & $0.017 *$ \\
\hline VI and OC & 1.019 & 0.105 & $0.000 *$ \\
\hline OC and HI & 0.751 & 0.105 & $0.000 *$ \\
\hline
\end{tabular}

*Significant at 0.05 level of confidence. (df $18=0.05) \mathrm{NS}=$ Not significant.

Table-12: Result of ' $t$ ' test for flexibility at immediate after exercise condition for different groups

\begin{tabular}{|l|l|l|c|}
\hline SPSG & Mean Difference & SED & 't' value \\
\hline HI and VI & 1.500 & 0.847 & $0.088 \mathrm{NS}$ \\
\hline VI and OC & 4.100 & 0.847 & $0.000^{*}$ \\
\hline OC and HI & 2.600 & 0.847 & $0.005^{*}$ \\
\hline
\end{tabular}

*Significant at 0.05 level of confidence. (df $18=0.05) \mathrm{NS}=$ Not significant.

In Table 10, 11 and 12 ' $\mathrm{t}$ ' ratio $\mathrm{df} 28=2.05$ it was observed that HI and VI group in respect ' $t$ ' value is not significant but other two groups VI Vs. OC, OC Vs. HI groups results are significant at 0.05 level of confidence ( $\mathrm{P}$ values $0.000,0.000)$ respectively.

\section{Graphical comparison of means of Height, Weight and $\mathrm{BMI}$ of $\mathrm{HI}, \mathrm{VI}$ and $\mathrm{OC}$}

Present study found that the HI, VI and OC SPSG were same in respect of health status. Among these SPS groups VI group had superior health status among other two groups.

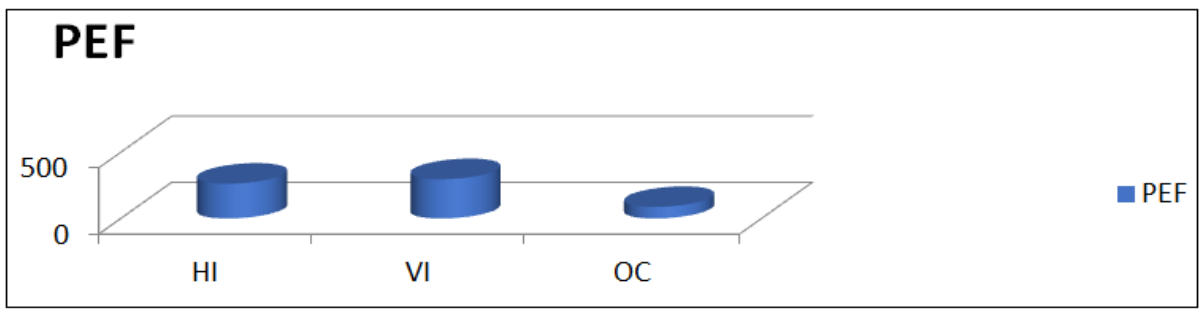

Fig-1: Comparison of PEF 


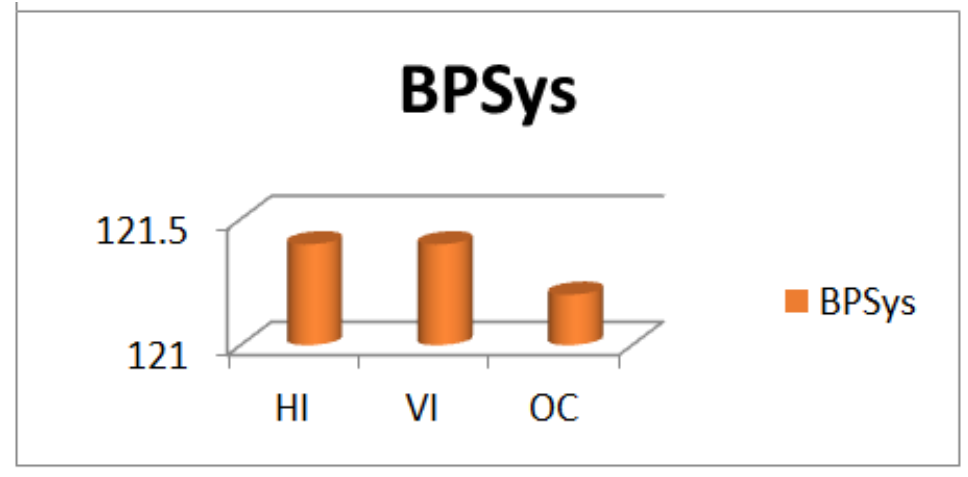

Fig-2: Comparison of BPSys

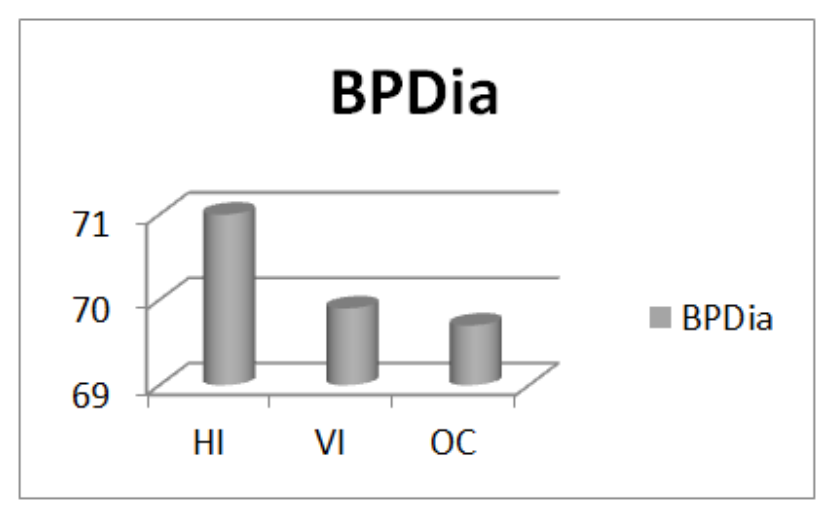

Fig-3: Comparison of BPDia

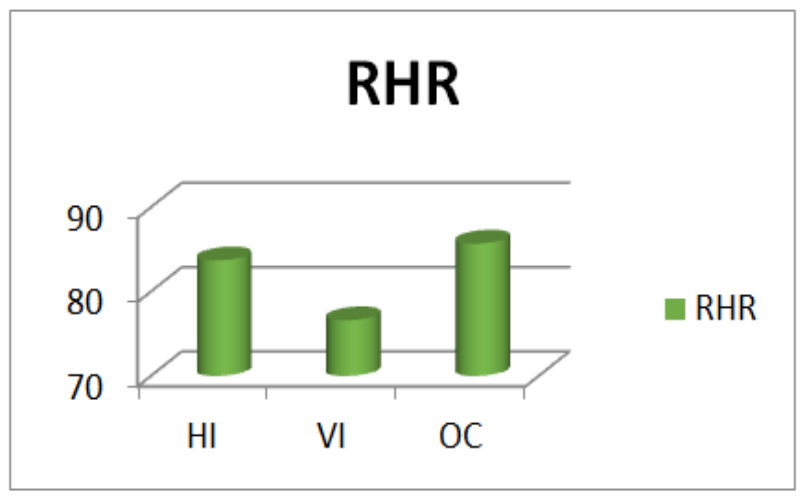

Fig-4: Comparison of RHR

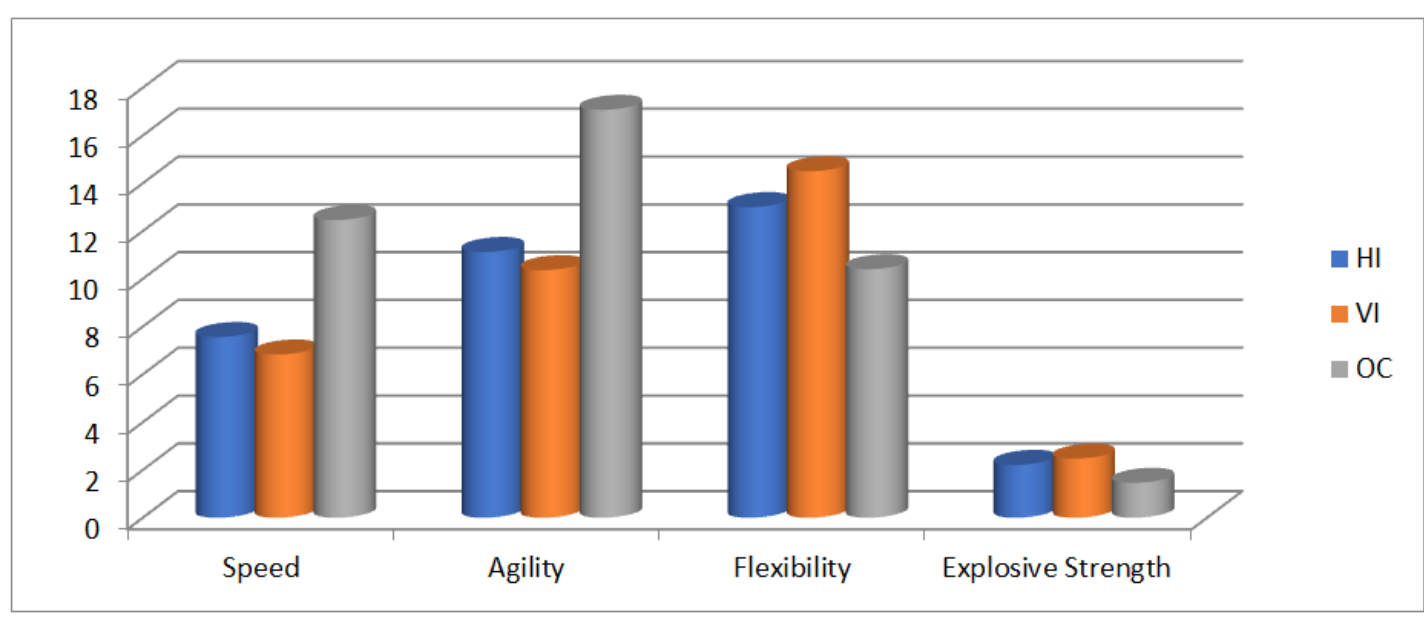

Fig-5: Comparison of speed, agility, flexibility and explosive strength among HI, VI and OC SPS Groups

\section{TESTING OF HYPOTHESES}

H1: The first hypothesis of this study stated as there will be significant differences in health status between the different categories of challenged students. Findings revealed that BMI was significantly different for HI, VI and $\mathrm{OH}$ SPS. Thus the first hypothesis was accepted for this study.

$\mathrm{H} 2$ : The second hypothesis was formulated in this study as there will be not significant differences in motor fitness variables, but in present study at 0.05 level of confidence. We got the significant relation for (speed, flexibility, agility, explosive strength) of HI,
VI and OC SPSG, that means null hypothesis rejected at 0.05 level for this study.

H3: The third hypothesis was also formulated in this study as there will be no significant differences in physiological fitness variables. But in our present study we got significant result for PEF and BPDia of HI, VI and OC SPS at 0.05 level of confidence. So that null hypothesis rejected for this two variables in this present study.

\section{DISCUSSION}

Findings indicated that mean and standard deviation of height of HI, VI and OC were $161.1 \pm 6.56$; 
$150.8 \pm 12.48$ and $150.7 \pm 13.51$ respectively. The mean and standard deviation of weight of HI, VI and OC were $41.7 \pm 6.18 ; 47.1 \pm 9.3$ and $40.3 \pm 6.49$ respectively. The mean and standard deviation of BMI of HI, VI and OC were $16.07 \pm 2.31 ; 20.86 \pm 3.94$ and $17.8 \pm 2.24$ respectively. Results indicated that F-value for height and weight for SPS were 2.895 and 2.314 and these Fvalues were not significant statistically. The F-value for BMI of SPS was 5.298 and this value found statistically significant. The findings about height, weight and BMI have shown that HI group of SPS were superior in height than other two groups. The VI group of SPS had higher weight than other two groups of SPS and BMI of VI group also found higher than the HI and OC groups of SPS in this study. Thus study found that the HI, VI and OC SPS were same in respect of height and weight. But the VI SPS had superior health status among three categories of SPS. This group had significantly higher Health status than other two groups [8].

The physiological variable PEF, BPDia were found not much more different for the HI, VI and OC SPS and in motor fitness like flexibility, speed, agility and explosive strength have significant difference between HI, VI and OC SPSG [9].

\section{CONCLUSSION}

1. It can be concluded from the results of the that among the SPS Group in respect of BMI Visually Impaired Group was more healthy than Hearing Impaired and orthopedically challenged SPS Groups.

2. From physiological point of view visually impaired group more fit among the three SPS groups. That means visually impaired groups cardio respiratory function effectively in better condition than their counter part.

3. In respect of motor fitness variables (speed, agility and explosive leg strength) visual groups more strong than other two groups. Needless to say orthopedically challenged students most of all had upper body related problem.

4. In comparison of personal, physiological and motor fitness related variables among three SPS Groups orthopedically challenged group were less active than other two groups of students.

5. In respect of all motor fitness variables VI group were higher speed, agility than of the two groups.

6. In respect of all motor fitness variables OC SPS group were higher in flexibility and explosive strength. In this study we saw all OC SPS group was orthopedically challenged in upper body related. So to perform flexibility and standing board jump were not affect their performance.

\section{RECOMMENDATIONS}

1. 1Similar study may be conducted on the older adult special population.

2. Similar study may be done on children and infancy population having different physical and mental disabilities.

3. Same study may be done on the girl's population having different physical and mental disabilities.

4. Other SPS groups of students can be considered for the future investigations.

5. SPS Groups of students may be compared with normal students in same level and on same variables.

6. Psychological variables also may be considered for the future investigation.

7. Similar study may also be conducted with the subjects of different age and level of participation with large populations.

\section{REFERENCES}

1. Mondal, L. K., \& Chakraborty, P. (2010). Comparative study of creative Motor Response Personality and Sociability between normal and A Journal on orthopedically challenged person, Unmesh Physical Education, 6(2):56-78.

2. Goodman, J., \& Hopper, C. (1992). Hearing Impaired children and Youth: A review of psychomotor behaviour. Adapted Physical Activity Quarterly. 9:214-234.

3. Winnick, J. P., \& Short, F. X. (1986). Physical Fitness of Adolescents with Auditory Impairments. Adapted Physical Activity Quarterly.

4. Schemidt, S. (1985). Hearing Impaired students in physical education. Adapted Physical Activity Quarterly, 2:300-306.

5. Langdale, C. J. (1984). The effect of Balance Instruction on balance proficiency of pre-natal and post natal deaf boys. Unpublished Master Thesis. California State Polytechnic University

6. Hottendorf, E. (1984). Main streaming deaf and hearing children in dance classes. Journal of Physical Education. Recreation and Dance, 60(9):54-55.

7. Harold, M. B., \& McGee, R. (1979). A Practical Approach to Measurement in Phy. Edn. (Philadelphia; Lea and Febiger), 114.

8. Paneella, L. (1979). Motor Ability and the Deaf: Research Implications. American ArUlals of the Deaf, 124:366-372.

9. Robert, V. H. (1973). Physicalfitness: the Pathway to healthful living (St.Lousis; The CV Mosby Company), 93-94. 